\title{
Risk of injury associated with bodychecking experience among youth hockey players
}

\author{
Carolyn Emery BScPT PhD, Jian Kang PhD, lan Shrier MD PhD, Claude Goulet PhD, Brent Hagel PhD, \\ Brian Benson MD PhD, Alberto Nettel-Aguirre PhD, Jenelle McAllister MSc, Willem Meeuwisse MD PhD
}

See also editorial by Ackery and Detsky on page 1235 and at www.cmaj.ca/lookup/doi/10.1503/cmaj.110634.

\begin{abstract}
Background: In a previous prospective study, the risk of concussion and all injury was more than threefold higher among Pee Wee ice hockey players (ages 11-12 years) in a league that allows bodychecking than among those in a league that does not. We examined whether two years of bodychecking experience in Pee Wee influenced the risk of concussion and other injury among players in a Bantam league (ages 13-14) compared with Bantam players introduced to bodychecking for the first time at age 13 .
\end{abstract}

Methods: We conducted a prospective cohort study involving hockey players aged 13-14 years in the top $30 \%$ of divisions of play in their leagues. Sixty-eight teams from the province of Alberta ( $n=995)$, whose players had two years of bodychecking experience in Pee Wee, and 62 teams from the province of Quebec $(n=976)$, whose players had no bodychecking experience in Pee Wee, participated. We estimated incidence rate ratios (IRRs) for injury and for concussion.

Results: There were 272 injuries (51 concussions) among the Bantam hockey players who had bodychecking experience in Pee Wee and
244 injuries (49 concussions) among those without such experience. The adjusted IRRs for game-related injuries and concussion overall between players with bodychecking experience in Pee Wee and those without it were as follows: injury overall 0.85 (95\% confidence interval $[\mathrm{Cl}] 0.63$ to 1.16$)$; concussion overall 0.84 ( $95 \% \mathrm{Cl} 0.48$ to 1.48 ); and injury resulting in more than seven days of time loss (i.e., time between injury and return to play) 0.67 (95\% $\mathrm{Cl} 0.46$ to 0.99 ). The unadjusted IRR for concussion resulting in more than 10 days of time loss was 0.60 (95\% Cl 0.26 to 1.41$)$.

Interpretation: The risk of injury resulting in more than seven days of time loss from play was reduced by $33 \%$ among Bantam hockey players in a league where bodychecking was allowed two years earlier in Pee Wee compared with Bantam players introduced to bodychecking for the first time at age 13. In light of the increased risk of concussion and other injury among Pee Wee players in a league where bodychecking is permitted, policy regarding the age at which hockey players are introduced to bodychecking requires further consideration.
Competing interests: None declared.

This article has been peer reviewed.

Correspondence to: Carolyn Emery, caemery@ucalgary.ca

CMAJ 2011. DOI:10.1503 /cmaj.101540
$\mathrm{R}$ ates of participation in youth-level ice hockey are high in North America. ${ }^{1,2}$ There is growing concern regarding the impact of concussion in this population..$^{3-5}$ Bodychecking is the reported mechanism for $45 \%$ $86 \%$ of injuries in youth ice hockey. ${ }^{5-11}$ Internationally, the age group at which bodychecking is introduced varies. In Canada, bodychecking is introduced in Pee Wee leagues (ages 11-12 years), except in the province of Quebec, where it is introduced in Bantam (ages 13-14). ${ }^{12}$

The age at which bodychecking should be introduced is controversial. We recently reported that the risk of injury and concussion in a Pee Wee league that allows bodychecking was more than threefold higher than in a Pee Wee league that does not allow bodychecking. ${ }^{9}$ Findings from systematic reviews support these findings. ${ }^{13,14}$

Injury rates may increase when players begin to learn bodychecking, because it is a new skill. If so, injury rates would be expected to be higher among players without bodychecking experience in Pee Wee (i.e., those in Quebec) than among players introduced to bodychecking two years earlier in Pee Wee (e.g., in Alberta). We examined whether the risk of concussion and other injury among hockey players in Bantam leagues differed between players with and those without bodychecking experience in Pee Wee. 


\section{Methods}

\section{Study design and participants}

We conducted a prospective cohort study over a season of play (2008/09) one year after an initial cohort study for which we had recruited Pee Wee players (ages 11-12) in the same leagues. . Our current study population comprised Bantam hockey players (ages 13-14) in the provinces of Alberta and Quebec. Cohorts were defined by whether they played in the Alberta league, which allowed bodychecking in Pee Wee, or in the Quebec league, which introduced bodychecking only in Bantam. The inclusion criteria were the same as those in our earlier study ${ }^{9}$ except that players were 13-14 years of age during the season of play and were in the top $30 \%$ of level of play, where bodychecking is allowed in both provinces.

Written informed consent was obtained from each player and from his or her parent or guardian, as per the ethics offices at the University of Calgary, University of Alberta, McGill University, Université de Montréal and Laval University.

A sample size of 1944 was determined necessary for a minimally important incidence rate ratio (IRR) of 0.5 or greater reduction in harm, based on an expected concussion rate of 1 per 1000 player-hours in the Alberta cohort, and adjusting for clustering and an anticipated dropout rate of $10 \%$ (two-sided test, $\alpha=0.05, \beta=0.2$ ). ${ }^{15}$

\section{Data collection}

The injury surveillance system was previously validated in youth ice hockey and was consistent with that used in our earlier cohort study involving Pee Wee players during the previous playing season. ${ }^{69}$ The following four data-collection documents were used: a preseason baseline questionnaire, which included the Sport Concussion Assessment Tool ${ }^{16}$ a questionnaire about attitudes toward bodychecking; ${ }^{17}$ a weekly exposure sheet documenting individual participation in practices and games; and an injury report form.

All hockey-related injuries that required medical attention or that resulted in the inability to complete a session or in time loss (i.e., time between injury and return to play) were identified by the team designate or therapist and recorded on an injury report form. All players with an identified injury or suspected concussion were assessed by a team therapist (i.e., physiotherapist, certified athletic therapist or senior athletic therapy student) who had been trained by a study physician. All players with a suspected concussion or time loss from play of more than seven days were recommended for review by a study sports medicine physician. Standardized follow-up and return-to- play guidelines, based on international concussion consensus guidelines, ${ }^{18}$ were followed by all study physicians and study therapists.

In addition, we collected information on other previously suggested risk factors. ${ }^{9}$ These risk factors included year of play (first or second), previous injury in the past year, previous concussion (ever), player's weight, level of play (top 30\% of the Bantam study cohort playing AAA or AA hockey in Alberta and AA in Quebec v. lower $70 \%$ of the cohort), position of player reported at baseline (defence, forward or goalie) and attitudes toward bodychecking. ${ }^{6,9}$ Weight was dichotomized at the 25 th percentile $(52 \mathrm{~kg})$ because we considered that the smallest players would be at greatest risk of injury. Attitude toward bodychecking was dichotomized at the 75 th percentile (score of 36 out of 55 on the bodychecking questionnaire) because we considered that players with higher total scores (i.e., a more positive attitude toward bodychecking) would be at greatest risk of injury.

\section{Outcome measures}

The primary outcome measure was the incidence of all injury and concussion among hockey players with and without previous bodychecking experience in Pee Wee. The secondary outcome measures were the incidence of injury resulting in more than 7 days of time loss from hockey (i.e., not including slight and minimal injuries, based on previous consensus agreement on injury definitions $\mathrm{s}^{19}$ ) and the incidence of concussion resulting in more than 10 days of time loss from hockey.

Concussions were included in the analysis if they met the study definition of a reportable injury based on the therapist's assessment and the Sport Concussion Assessment Tool and the definition of concussion based on consensus guidelines. ${ }^{18} \mathrm{~A} 10$ day cut-off for time loss due to concussion was chosen because it has been suggested as a marker to retrospectively distinguish severity of concussion and has been supported in the literature for male sport participants. ${ }^{16,20-24}$

\section{Statistical analysis}

Baseline characteristics were compared between the two study cohorts and between injured and uninjured players.

We estimated IRRs and 95\% confidence intervals (CIs) for the following outcomes using Poisson regression analysis: injury overall, injury resulting in more than seven days of time loss from play and concussion overall. In each model, we included player-hours as an offset, accounting for clustering by team effect and adjusting for all included covariables (year of play, previous injury or concussion, size of player, position of 
player [centre, wing, defence or goalie] and attitudes toward bodychecking). Because of the smaller event rates for concussion resulting in time loss of more than 10 days from hockey, we limited the Poisson regression analysis for this outcome to univariable analyses (still accounting for clustering effects by team). Given the expectation of effect modification by type of session (game v. practice), we stratified analyses by this variable for all injury definitions. An IRR greater than 1.0 indicates an increased risk of concussion or other injury.

\section{Results}

A total of 172 teams were approached to participate in the study (91 in Alberta and 81 in Quebec). A total of 130 teams participated: 68 in the province of Alberta $(n=995 ; 605$ in Calgary and 390 in Edmonton) and 62 teams in the province of Quebec ( $n=976 ; 591$ in Montréal and 385 in Québec City). Table 1 summarizes the baseline characteristics of the study cohorts.

The median number of hours of game time per player over the 2008/09 season was 51.9

Table 1: Baseline characteristics of 1971 hockey players in Bantam leagues (ages 13-14 years) with and without previous bodychecking experience in Pee Wee leagues (ages 11-12 years), 2008/09

\begin{tabular}{|c|c|c|c|c|}
\hline \multirow[b]{2}{*}{ Characteristic } & \multicolumn{2}{|c|}{ Injured } & \multicolumn{2}{|c|}{ Not injured } \\
\hline & $\begin{array}{c}\text { Previous bodychecking } \\
\text { experience* } \\
n=223\end{array}$ & $\begin{array}{c}\text { No previous } \\
\text { bodychecking experience* } \\
n=203\end{array}$ & $\begin{array}{c}\text { Previous bodychecking } \\
\text { experience* } \\
n=772\end{array}$ & $\begin{array}{c}\text { No previous } \\
\text { bodychecking experience* } \\
n=773\end{array}$ \\
\hline \multicolumn{5}{|l|}{ Sex, no. (\%) } \\
\hline Male & $222(99.6)$ & $200(98.5)$ & 768 (99.5) & 766 (99.1) \\
\hline Height, cm, mean (SD) & $\begin{array}{c}n=217 \\
168.2 \quad(9.5)\end{array}$ & $\begin{array}{c}n=202 \\
168.3(8.4)\end{array}$ & $\begin{array}{c}n=753 \\
167.5 \quad(9.4)\end{array}$ & $\begin{array}{c}n=767 \\
168.1 \quad(8.3)\end{array}$ \\
\hline Weight, kg, mean (SD) & $\begin{array}{c}n=219 \\
58.6(10.8)\end{array}$ & $\begin{array}{l}n=202 \\
59.4(9.8)\end{array}$ & $\begin{array}{c}n=750 \\
57.3(10.5)\end{array}$ & $\begin{array}{l}n=768 \\
60.0(10.1)\end{array}$ \\
\hline $\begin{array}{l}\text { Year of play in Bantam } \\
\text { league, no. }(\%)\end{array}$ & $n=223$ & $n=203$ & $n=772$ & $n=773$ \\
\hline \multicolumn{5}{|l|}{ Level of play } \\
\hline Top 30\% & $117(52.5)$ & 75 (36.9) & 262 (33.9) & $233(30.1)$ \\
\hline Lower $70 \%$ & $106(47.5)$ & $128(63.1)$ & $510(66.1)$ & $540(69.9)$ \\
\hline \multicolumn{5}{|l|}{ Position of player } \\
\hline Forward & $130(58.3)$ & $119(58.6)$ & $426(55.2)$ & $407(52.7)$ \\
\hline Defence & 75 (33.6) & $70(34.5)$ & $238(30.8)$ & 259 (33.5) \\
\hline Goalie & $15(6.7)$ & $13(6.4)$ & 95 (12.3) & $101(13.1)$ \\
\hline Data missing & $3(1.3)$ & $1(0.5)$ & $13(1.7)$ & $6 \quad(0.8)$ \\
\hline \multicolumn{5}{|l|}{ Previous injury (past year) } \\
\hline \multicolumn{5}{|l|}{ Previous concussion (ever) } \\
\hline Data missing & $5 \quad(2.2)$ & $1(0.5)$ & $19(2.5)$ & $13(1.7)$ \\
\hline $\begin{array}{l}\text { Attitude toward } \\
\text { bodychecking, mean } \\
\text { score (SD) } \dagger\end{array}$ & $\begin{array}{l}n=215 \\
38.6 \quad(6.0)\end{array}$ & $\begin{array}{l}n=191 \\
36.9 \quad(6.9)\end{array}$ & $\begin{array}{l}n=721 \\
37.7 \quad(6.2)\end{array}$ & $\begin{array}{l}n=724 \\
36.4 \quad(7.0)\end{array}$ \\
\hline $\begin{array}{l}\text { Note: SD = standard deviat } \\
\text { *In Pee Wee leagues. } \\
\text { tTotal score possible = 55; }\end{array}$ & 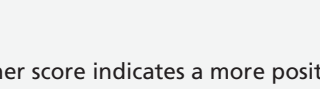 & trity & & \\
\hline
\end{tabular}


(interquartile range [IQR] 41.2-75.2) hours among the hockey players who had bodychecking experience in Pee Wee and 45.4 (IQR 34.559.5) hours among those who did not have such experience. The corresponding median number of hours of practice time were 32.8 (IQR 24.844.0) hours and 37.8 (IQR 29.0-50.1) hours.
A total of 272 injuries (51 concussions) were reported during 96907 player-hours among the hockey players with previous bodychecking experience in Pee Wee. A total of 244 injuries (49 concussions) were reported during 85464 player-hours among players without such bodychecking experience. The

Table 2: Game-related outcomes among 1971 hockey players in Bantam leagues (ages 13-14 years) with and without previous bodychecking experience in Pee Wee leagues (ages 11-12 years), 2008/09

\begin{tabular}{|c|c|c|c|c|c|c|c|c|}
\hline \multirow[b]{3}{*}{ Variable } & \multicolumn{8}{|c|}{ Outcome; previous bodychecking experience in Pee Wee leagues } \\
\hline & \multicolumn{2}{|c|}{ Injury overall } & \multicolumn{2}{|c|}{$\begin{array}{l}\text { Injury with }>7 \text { days } \\
\text { of time loss* }\end{array}$} & \multicolumn{2}{|c|}{ Concussion overall } & \multicolumn{2}{|c|}{$\begin{array}{c}\text { Concussion with }>10 \text { days } \\
\text { of time loss* }\end{array}$} \\
\hline & Experience & No experience & Experience & No experience & Experience & No experience & Experience & No experience \\
\hline No. of players & 242 & 210 & 91 & 100 & 48 & 42 & 14 & 11 \\
\hline No. of player-hours & 60644 & 46222 & 60644 & 46222 & 60644 & 46222 & 60644 & 46222 \\
\hline $\begin{array}{l}\text { Incidence rate } \\
\text { ratiot }(95 \% \mathrm{Cl})\end{array}$ & $\begin{array}{c}0.88 \\
(0.67 \text { to } 1.16)\end{array}$ & ref & $\begin{array}{c}0.70 \\
\text { (0.49 to } 0.99)\end{array}$ & ref & $\begin{array}{c}0.87 \\
\text { (0.51 to } 1.50)\end{array}$ & ref & $\begin{array}{c}0.60 \\
(0.26 \text { to } 1.41)\end{array}$ & ref \\
\hline $\begin{array}{l}\text { Absolute risk } \\
\text { reduction }(95 \% \mathrm{Cl})\end{array}$ & \multicolumn{2}{|c|}{$-0.55(-1.35$ to 0.24$)$} & \multicolumn{2}{|c|}{$-0.65(-1.18$ to 0.13$)$} & \multicolumn{2}{|c|}{$-0.12(-0.47$ to 0.24$)$} & \multicolumn{2}{|c|}{$-0.12(-0.31$ to 0.07$)$} \\
\hline
\end{tabular}

Table 3: Risk factors associated with game-related concussion or other injury among 1971 hockey players in Bantam leagues (ages 13-14 years) with and without previous bodychecking experience in Pee Wee leagues (ages 11-12 years), 2008/09

\begin{tabular}{|c|c|c|c|c|}
\hline \multirow[b]{2}{*}{ Risk factor } & \multicolumn{4}{|c|}{ Outcome; adjusted incidence rate ratio* $(95 \% \mathrm{Cl})$} \\
\hline & Injury overall & $\begin{array}{c}\text { Injury with } \\
>7 \text { days time losst }\end{array}$ & Concussion overall & $\begin{aligned} & \text { Concussion with } \\
> & 10 \text { days time loss } t\end{aligned}$ \\
\hline $\begin{array}{l}\text { Previous bodychecking experience } \\
\text { in Pee Wee league (v. none) }\end{array}$ & 0.85 (0.63 to 1.16$)$ & 0.67 (0.46 to 0.99$)$ & 0.84 (0.48 to 1.48$)$ & $0.60(0.26$ to 1.41$)$ \\
\hline $\begin{array}{l}\text { First year of play in Bantam } \\
\text { league (v. second year) }\end{array}$ & 1.40 (1.10 to 1.80$)$ & 1.48 (1.06 to 2.07$)$ & 1.64 (0.99 to 2.69$)$ & 2.57 (1.04 to 6.36$)$ \\
\hline $\begin{array}{l}\text { Previous injury in past year } \\
\text { (v. no previous injury) }\end{array}$ & $1.39(1.13$ to 1.71$)$ & 1.91 (1.45 to 2.51$)$ & NA & NA \\
\hline $\begin{array}{l}\text { Previous concussion ever } \\
\text { (v. no previous concussion) }\end{array}$ & NA & NA & 1.87 (1.19 to 2.94$)$ & 2.40 (1.01 to 5.67$)$ \\
\hline Weight $\leq 52 \mathrm{~kg}(\mathrm{v} .>52 \mathrm{~kg})$ & $1.03(0.79$ to 1.33$)$ & $0.92(0.62$ to 1.35$)$ & 1.25 (0.71 to 2.21$)$ & 0.89 (0.38 to 2.12$)$ \\
\hline $\begin{array}{l}\text { Level of play in top } 30 \% \\
(v . \text { lower } 70 \%)\end{array}$ & $1.02(0.75$ to 1.38$)$ & $1.13(0.78$ to 1.64$)$ & $0.90(0.52$ to 1.56$)$ & 0.80 (0.35 to 1.79$)$ \\
\hline Defence position ( $v$. forward) & 0.88 (0.70 to 1.09$)$ & $0.89(0.64$ to 1.23$)$ & 0.84 (0.50 to 1.41$)$ & 0.94 (0.42 to 2.11$)$ \\
\hline Goalie position (v. forward) & 0.34 (0.18 to 0.65$)$ & 0.35 (0.14 to 0.85$)$ & 0.45 (0.14 to 1.44$)$ & 0 \\
\hline $\begin{array}{l}\text { More positive attitude toward } \\
\text { bodychecking (score } \geq 36 / 55 \text { ) ( } \mathrm{v} \text {. less } \\
\text { positive attitude }[\text { score }<36.55] \text { ) }\end{array}$ & $1.01(0.82$ to 1.25$)$ & 0.99 (0.71 to 1.38$)$ & 1.10 (0.68 to 1.78$)$ & 0.92 (0.35 to 2.40$)$ \\
\hline \multicolumn{5}{|c|}{$\begin{array}{l}\text { Note: } \mathrm{Cl}=\text { confidence interval, } \mathrm{NA}=\text { not applicable. } \\
\text { *Incidence rate ratios for all injury, all concussion and injury resulting in more than seven days of time loss from hockeyt were based on Poisson regression analysis } \\
\text { offset for player-hours and adjusted for clustering by team and covariables (year of play, previous injury or concussion, player size, level of play, position of player and } \\
\text { attitude toward bodychecking). Incidence rate ratios for concussion resulting in more than } 10 \text { days of time losst were based on Poisson regression analysis offset for } \\
\text { player-hours and adjusted for clustering by team only. An incidence rate ratio greater than } 1.0 \text { indicates an increased risk of concussion or other injury. } \\
\text { tTime loss = time between injury and return to play. }\end{array}$} \\
\hline
\end{tabular}


rates of game-related injuries per 1000 playerhours were similar in the two study cohorts (Table 2). The IRR between the study cohorts for injury during practice hours was $1.00(95 \%$ CI 0.59 to 1.72 ).

Table 3 summarizes the results of the adjusted multiple Poisson regression models for risk factors associated with game-related injury overall, concussion overall and injury resulting in more than 7 days of time loss from hockey, as well as results of the unadjusted models for concussion resulting in more than 10 days of time loss from play. The IRRs for game-related injury between players with bodychecking experience in Pee Wee and those without it were 0.85 for injury overall, 0.84 for concussion overall and 0.60 for concussion resulting in more than 10 days of time loss; 95\% CIs for each included the null value of 1.0 , which suggests that the observed differences between the cohorts could have been due to chance. For injury resulting in more than seven days of time loss from play, the IRR of 0.67 (95\% CI 0.46 to 0.99 ) indicated a $33 \%$ reduction in the risk of injury among the players who had bodychecking experience in Pee Wee.

Previous injury and previous concussion were significant risk factors for injury and concussion, respectively (Table 3 ). Compared with being in the second year in the Bantam league, being in the first year was associated with an increased risk of injury overall, injury resulting in more than 7 days of time loss from hockey and con- cussion resulting in more than 10 days of time loss from hockey. Compared with being a forward, being a goalie was associated with a lower risk of injury overall and of injury resulting in more than seven days of time loss from hockey.

Game-related rates of injury by mechanism are summarized in Figure 1. The rate associated with bodychecking was higher than any other mechanism of injury in both study cohorts. The rate of injury from bodychecking did not differ significantly between the cohorts (IRR 0.82 , 95\% CI 0.59 to 1.15 ).

The head and shoulders were the most common locations of injury in both study cohorts (Table 4). The top three reported types of injury were contusion, concussion, and ligament sprain or dislocation (Table 4).

\section{Interpretation}

In this prospective cohort study involving hockey players in Bantam leagues (ages 13-14 years), we found that the risk of injury resulting in more than seven days of time loss from play was 33\% lower among players with two years of bodychecking experience in Pee Wee (ages 11-12) than among those without such bodychecking experience. The point estimates for the game-related IRRs indicated a $15 \%$ lower risk of injury overall, a $16 \%$ lower risk of concussion overall and a $40 \%$ lower risk of concussion resulting in more than 10 days of time loss

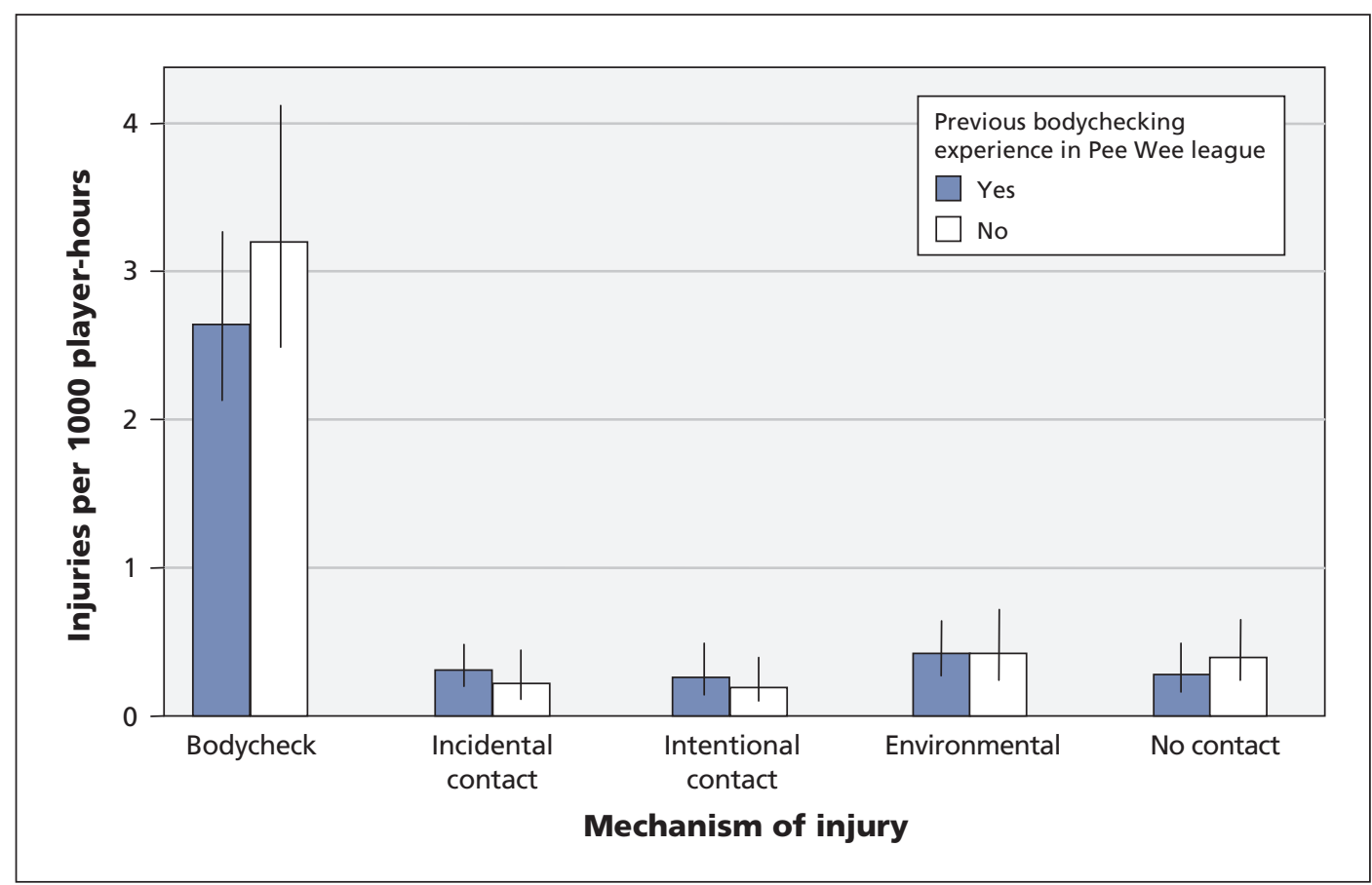

Figure 1: Game-related rates of injury per 1000 player-hours among 1971 hockey players in Bantam leagues (ages 13-14 years) with and without two years of bodychecking experience in Pee Wee (ages 11-12), by mechanism of injury, 2008/09. Error bars $=95 \%$ confidence intervals. 
among the players who had had bodychecking experience in Pee Wee; the 95\% CIs for these estimates, however, included the null value of 1.0, which suggests that the observed differences between the cohorts could have been due to chance.

In our earlier cohort study the previous year, which involved players in Pee Wee leagues (ages 11-12 years) in the top 60\% of divisions, the game-related rates of concussion and other injury per 1000 player-hours were 4.20 (95\% CI 3.49 to 5.07$)$ for injury and 1.47 (95\% 1.08 to 1.99) for concussion among players introduced to bodychecking in Pee Wee. ${ }^{9}$ These rates are similar to those among the Bantam players (ages 13-14) in the current study who had no bodychecking experience in Pee Wee. These findings suggest that the rates of injury and concussion are consistent among players when first introduced to bodychecking, whether in Pee Wee or Bantam. Consideration should be given also to the age at which a player is able to make an informed decision about playing under these conditions of increased risk, perhaps after they have finished a critical physical growth period that could be focused on skill development.

The rates of injury and concussion overall among the Bantam hockey players in our current study who had bodychecking experience in Pee Wee are consistent with results from other studies. ${ }^{6,25}$ Mechanisms, location and type of injury were also consistent with findings of other studies. ${ }^{6,11,25}$ A history of injury in the past year increased the risk of injury, and a history of concussion increased the risk of concussion, similar to findings of other reports. ${ }^{26}$ These risk factors may be related to incomplete healing or rehabilitation or to susceptibility to injury based on other factors (e.g., genetics, on-ice behaviours). Smaller player size was not found to be a risk factor among the players in the current study, in contrast to our study involving younger players in Pee Wee leagues. ${ }^{9}$

\section{Limitations}

Concussions were included if they met the study definition of a reportable injury based on the study therapist's assessment and the Sport Con-

Table 4: Rates of game-related injuries per 1000 player-hours among hockey players in Bantam leagues (ages 13-14 years) with and without previous bodychecking experience in Pee Wee leagues (ages 11-12 years), by location and type of injury, 2008/09

\begin{tabular}{|c|c|c|}
\hline \multirow[b]{2}{*}{ Location and type of injury } & \multicolumn{2}{|c|}{ Rate per 1000 player-hours* $(95 \% \mathrm{Cl})$} \\
\hline & $\begin{array}{c}\text { Previous bodychecking } \\
\text { experiencet }\end{array}$ & $\begin{array}{c}\text { No previous bodychecking } \\
\text { experiencet }\end{array}$ \\
\hline \multicolumn{3}{|l|}{ Location } \\
\hline Head/face & 0.79 (0.55 to 1.13$)$ & 0.95 (0.64 to 1.42$)$ \\
\hline Neck/throat & 0.15 (0.08 to 0.28$)$ & 0.09 (0.03 to 0.28$)$ \\
\hline Shoulder/clavicle & $0.79(0.55$ to 1.15$)$ & $0.74(0.52$ to 1.04$)$ \\
\hline Arm/elbow/forearm & $0.35(0.22$ to 0.55$)$ & 0.17 (0.09 to 0.33$)$ \\
\hline Wrist/hand & $0.46(0.32$ to 0.66$)$ & 0.58 (0.36 to 0.94$)$ \\
\hline Back/side & 0.41 (0.27 to 0.64$)$ & $0.61(0.36$ to 1.01$)$ \\
\hline Ribs/abdomen/pelvis & $0.15(0.08$ to 0.29$)$ & $0.30(0.17$ to 0.53$)$ \\
\hline Hip/groin/upper leg & $0.49(0.32$ to 0.76$)$ & 0.39 (0.24 to 0.64$)$ \\
\hline Knee & 0.48 (0.33 to 0.69$)$ & $0.63(0.43$ to 0.92$)$ \\
\hline Lower leg/ankle/foot & 0.15 (0.07 to 0.29 ) & 0.32 (0.19 to 0.56$)$ \\
\hline \multicolumn{3}{|l|}{ Type } \\
\hline Contusion & $0.94(0.69$ to 1.28$)$ & $1.06(0.73$ to 1.55$)$ \\
\hline Concussion & $0.79(0.55$ to 1.13$)$ & 0.91 (0.60 to 1.37$)$ \\
\hline Joint/ligament sprain/dislocation & $0.76(0.55$ to 1.04$)$ & $1.15(0.82$ to 1.60$)$ \\
\hline Fracture & 0.69 (0.48 to 1.00$)$ & 0.69 (0.48 to 1.01$)$ \\
\hline Muscle strain/tendonitis & $0.58(0.38$ to 0.87$)$ & $0.54(0.37$ to 0.80$)$ \\
\hline Abrasion/bleeding/burn/cut & 0.05 (0.02 to 0.15$)$ & 0.04 (0.01 to 0.17$)$ \\
\hline Other & $0.12(0.05$ to 0.26$)$ & 0.15 (0.06 to 0.37$)$ \\
\hline
\end{tabular}


cussion Assessment Tool. It is a limitation, however, that not all of the players were followed up with a physician. About $70 \%$ of the players with a reported concussion (35/49 in Alberta and 30/45 in Quebec) saw a physician. Although the concussion rate may have been underestimated, the number of missed concussions probably did not differ between the study cohorts because the training for team therapists was the same in both provinces.

Rules of play and qualifications of referees did not differ between the provinces; however, there was a reward system for fair play in Quebec, based on the number of penalty minutes called by referees. Although there was an emphasis on fair play in Alberta, there was no official reward system. However, a study of the effect of a fair-play reward system showed that rates of injury and the observed number of penalties did not differ between a Bantam league that rewarded teams through a fair-play point system for low penalty minutes and a Bantam league with no reward system. ${ }^{27}$ In addition, in our previous study involving Pee Wee hockey players (ages 11-12), where a fair-play reward system was in place in Edmonton but not in Calgary, the rates of injury between the two cities did not differ. ${ }^{9}$

Ideally, one group of hockey players in Pee Wee should be recruited and followed for four years to assess the change in rates of injury from ages 11-12 to ages 13-14 in a single cohort. Some players who were injured in the Pee Wee league in Alberta, where bodychecking is allowed, may have dropped out and not played in the Bantam league. This "depletion of susceptibles" in Alberta may have exaggerated differences in the rates of injury overall and of injury resulting in more than seven days of time loss from hockey observed in the current study; that is, the lower rates seen in Alberta may be attributable to a "survivor" effect and not to the protection conferred from bodychecking experience. This requires further investigation.

\section{Conclusion}

The risk of injury resulting in more than seven days of time loss from play was reduced by $33 \%$ among Bantam ice hockey players (ages 13-14 years) who had two years of bodychecking experience in Pee Wee (ages 11-12) compared with Bantam players introduced to bodychecking for the first time at age 13. These findings need to be interpreted in light of previous evidence of more than a threefold increased risk of concussion and all injury among players aged 11-12 years in a league where bodychecking is permitted. Policy regarding the age at which hockey players are introduced to bodychecking requires further consideration.

\section{References}

1. Annual report 2008. Ottawa (ON): Hockey Canada; 2008. Available: www.hockeycanada.ca/index.php/ci_id/55192/la_id /1.htm (accessed 2010 Feb. 18)

2. Annual report 2007-08. USA Hockey Inc.; 2008. Available: www .usahockey.com/uploadedFiles/USAHockey/Menu_About_USA _Hockey/USAH\%20Annual\%20Report\%200708_WEB.pdf (accessed 2010 Feb. 18).

3. Emery C, Meeuwisse WH, McAllister JR. Survey of sport participation and sport injury in Calgary and area high schools. Clin J Sport Med 2006;16:20-6.

4. Emery CA, Tyreman H. Sport participation, sport injury, risk factors and sport safety practices in Calgary and area junior high schools. Paediatr Child Health 2009;14:439-44.

5. Marchie A, Cusimano MD. Bodychecking and concussions in ice hockey: Should our youth pay the price? CMAJ 2003;169: 124-8.

6. Emery CA, Meeuwisse WH. Injury rates, risk factors, and mechanisms of injury in minor hockey. Am J Sports Med 2006; 34:1960-9.

7. Roy M, Bernard D, Roy B, et al. Body checking in peewee hockey. Phys Sportsmed 1989;17:119-26.

8. Roberts WO, Brust JD, Leonard B. Youth ice hockey tournament injuries: rates and patterns compared to season play. Med Sci Sports Exerc 1999;31:46-51.

9. Emery CA, Kang J, Shrier I, et al. Risk of injury associated with body checking among youth ice hockey players. JAMA 2010; 303:2265-72.

10. Benson B, Meeuwisse W. The risk of concussion associated with mouthguard use among professional ice hockey players [abstract]. Clin J Sport Med 2005;15:395.

11. Brust JD, Leonard BJ, Pheley A, et al. Children's ice hockey injuries. Am J Dis Child 1992;146:741-7.

12. Background on checking. Ottawa $(\mathrm{ON})$ : Hockey Canada. Available: www.hockeycanada.ca/index.php/ci_id/6862/la_id/1/ss_id /6887.htm (accessed 2011 June 2).

13. Warsh JM, Constantin SA, Howard A, et al. A systematic review of the association between body checking and injury in youth ice hockey. Clin J Sport Med 2009;19:134-44.

14. Emery CA, Hagel B, Decloe MD, et al. Risk factors for injury and severe injury in youth ice hockey: a systematic review of the literature. Inj Prev 2010;16:113-8.

15. Hayes RJ, Bennett S. Simple sample size calculations for cluster-randomized trials. Int J Epidemiol 1999;28:319-26.

16. Meeuwisse WH, Love EJ. Development, implementation, and validation of the Canadian Intercollegiate Sport Injury Registery. Clin J Sport Med 1998;8:164-77.

17. Emery CA, McKay CD, Campbell TS, et al. Examining attitudes towards body-checking, levels of emotional empathy, and levels of aggression in body-checking and non-body checking youth hockey leagues. Clin J Sport Med 2009;19: 207-15.

18. McCrory P, Johnston K, Meeuwisse W, et al. Summary and agreement statement of the 2nd International Conference on Concussion in Sport, Prague 2004. Br J Sports Med 2005;39: 196-204.

19. Fuller CW, Ekstrand J, Junge A, et al. Consensus statement on injury definitions and data collection procedures in studies of football (soccer) injuries. Clin J Sport Med 2006;16:97-106.

20. McCrory P, Meeuwisse W, Johnston K, et al. Consensus statement on concussion in sport: the 3rd international conference on concussion in sport held in Zurich, November 2008. Br J Sports Med 2009;43(Suppl 1):i76-90.

21. Broglio SP, Peutz T. The effect of sport concussion on neurocognitive function, self-report symptoms and postural control: a meta-analysis. Sports Med 2008;38:53-7.

22. Iverson G. Predicting slow recovery from sport-related concussion: the new simple-complex distinction. Clin J Sport Med 2007; 17:31-7.

23. Lau B, Lovell M, Collins M, et al. Neurocognitive and symptom predictors of recovery in high school athletes. Clin J Sport Med 2009;19:216-21.

24. Makdissi M. Is the simple versus complex classification of concussion a valid and useful differentiation? Br J Sports Med 2009;43(Suppl 1):i23-7.

25. Willer B, Kroetsch B, Darling S, et al. Injury rates in house league, select, and representative youth ice hockey. Med Sci Sports Exerc 2005;37:1658-63.

26. Emery CA. Risk factors for injury in child and adolescent sport: a systematic review of the literature. Clin J Sport Med 2003;13: 256-68.

27. Brunelle JP, Goulet C, Arguin H. Promoting respect for the rules and injury prevention in ice hockey: evaluation of the Fair-Play Program. J Sci Med Sport 2005;8:294-304. 
Affiliations: From the Sport Injury Prevention Research Centre (Emery, Kang, Benson, McAllister, Meeuwisse), Roger Jackson Centre for Health and Wellness Research, Faculty of Kinesiology, University of Calgary, Calgary, Alta.; the Department of Physical Education (Goulet), Faculty of Education, Laval University, Québec City, Que.; the Centre for Clinical Epidemiology and Community Studies (Shrier), Lady Davis Institute for Medical Research, Jewish General Hospital, McGill University, Montréal, Que.; and the Departments of Pediatrics (Emery, Hagel, Nettel-Aguirre) and Community Health Sciences (Emery, Hagel, Nettel-Aguirre, Meeuwisse), Faculty of Medicine, University of Calgary, Calgary, Alta.

Contributors: Carolyn Emery was the principal investigator for the study, had full access to all of the data and takes responsibility for the integrity of the data and accuracy of the analysis. She led the design, all research activities, analysis and manuscript preparation. Jian Kang was responsible for technical aspects of the data analysis and participated in the interpretation of data and the drafting of the manuscript Brent Hagel contributed to the design of the study, the analysis and interpretation of data, and critically reviewed the manuscript. Ian Shrier contributed to the design of the study, led all research activities in Montréal and critically reviewed the manuscript. Claude Goulet contributed to the design of the study, led all research activities in Québec City and critically reviewed the manuscript. Brian Benson contributed to the design of the study, led the team regarding clinical follow-up for concussion and critically reviewed the manuscript. Alberto Nettel-Aguirre contributed to the technical aspects of the plan for data analysis at the proposal stage, participated in the interpretation of data and critically reviewed the manuscript. Jenelle McAllister coordinated all research activities for the study at all stages, participated in the acquisition of data and the drafting of the manuscript. Willem Meeuwisse contributed to the design of the study, the interpretation of data and critically reviewed the manuscript. All of the authors approved the final version of the manuscript submitted for publication.

Funding: This study was funded by the Canadian Institutes of Health Research (CIHR) and the Max Bell Foundation. Carolyn Emery is supported by a Population Health Investigator Award from the Alberta Heritage Foundation, a CIHR New Investigator Award and an Alberta Children's Hospital Foundation Professorship in Pediatric Rehabilitation. Ian Shrier is supported by the Senior Clinician Scientist Program of the Fonds de la recherche en santé du Quebec. Brent Hagel holds the Alberta Children's Hospital Foundation Professorship in Child Health and Wellness, funded through the support of an anonymous donor and the Canadian National Railway Company; he is also supported by a Population Health Investigator Award from the Alberta Heritage Foundation for Medical Research and a CIHR New Investigator Award. The role of the sponsors and funding bodies was to provide financial support for this research and the translation of the findings to all community partners.

Acknowledgements: This study was made possible by the cooperation of Hockey Calgary, Hockey Edmonton, Hockey Quebec, Hockey Alberta, Hockey Canada and the Quebec Ministry of Education, Leisure and Sport. This research could not have been completed without the cooperation of many Pee Wee players, parents, coaches, team designates, physiotherapists, athletic therapists, student therapists and study physicians. 